تاريخ الحركة العمالية في العلق

$$
\text { مدير مركز الدراسات الإقليمية -جامعة الموصل خلاهل }
$$

مستخلص البحث

ارتبطت الحركة العمالية في العرلق، بالتطورات التي حدثت من منذ أواخر القرن

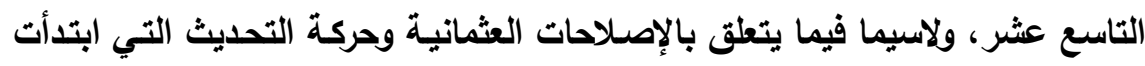

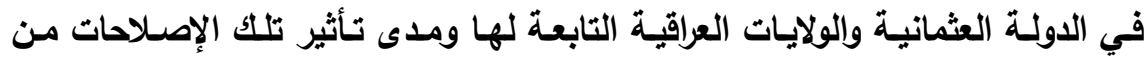

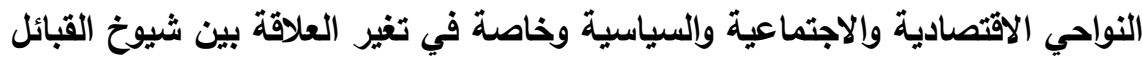

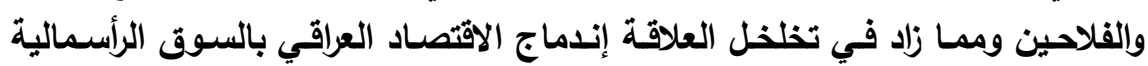

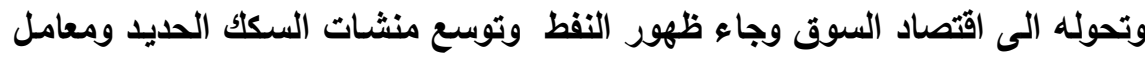

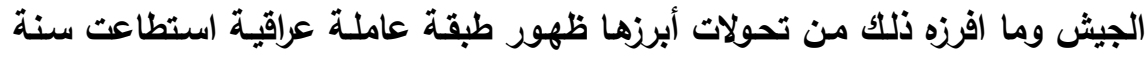

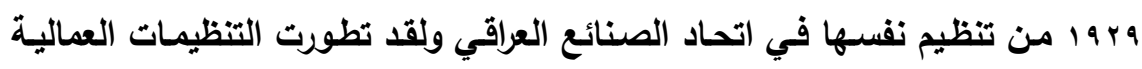

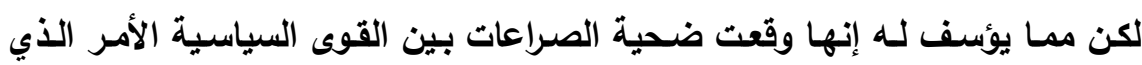
أبعدها في كثير من الأحيان عن ممارسـة دورها المهني والنقابي والدراسـة تلتابع كل

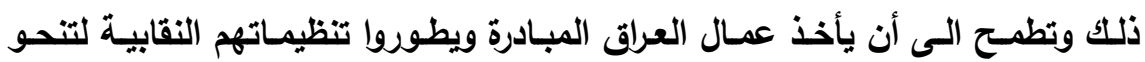


ارتبطت الحركة العمالية في العراق، بالتطورات التي حدثت منذ أواخر

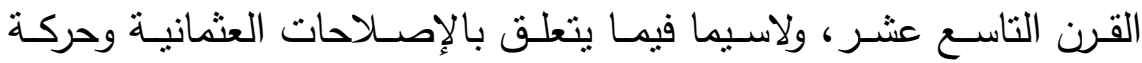
التحديث التي ابتدأت في الدولة العثمانية والولايات العراقية التابعة لها ومدى بالاهى تأثنر تلك الإصلاحات وخاصـة في مجال إصلاح نظام الأراضي، وتطبيق

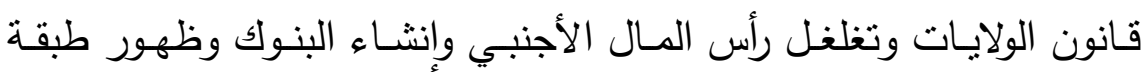

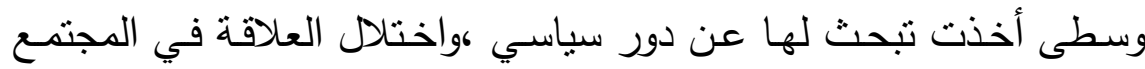
العراقي بعد تملك شيوخ العثائر والماكين الغائبين للأراضي وتغير العيني لعلاقة بين الثيخ وأفراد عشيرته في الديرة.

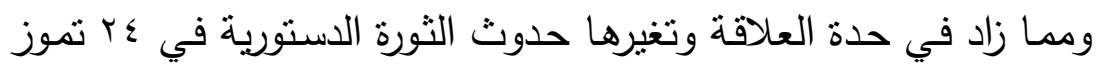

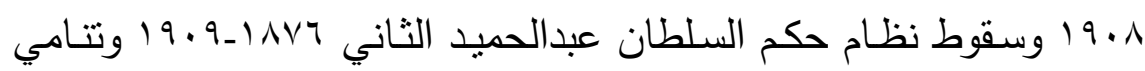
الثعور القومي، وتأسيس أحزاب وجمعيات تتادي بالاستقلال ونتكيل دول قوميـة. وكان للحرب العالميـة الأولى ودخول الدولة العثمانيـة للحرب إلى ولى

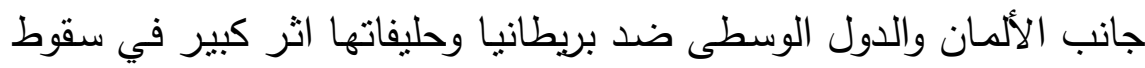

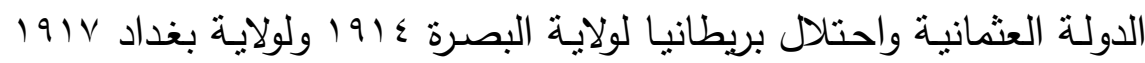
ولولاية الموصل 1918 وظهور العراق دولة حديثة مؤلفة من الولايات الثناث وتأسيس الجيش العراقي ومبايعة الأمير فيصل بن الثريف حسين ملكا على دولى دوله العـراق فـي آب ابو أواجـراء انتخابـات المجلس التأسيسـي (البرلمـان)، وتتامي الحركة الوطنية وتطور الصحافة وصدور قانون لتشجيع الصناعة

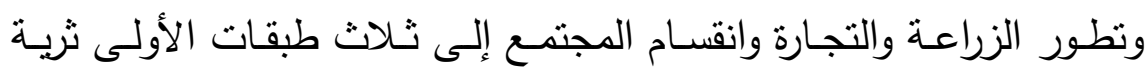
والثانية متوسطة والثالثة فقيرة. لقد كـان للتغيـرات التي شـهـها المجتمـع العراقي وخاصــة بعد انـدماج

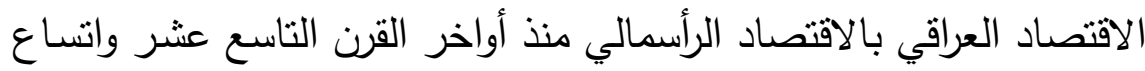
حركة الاستيراد والتصدير وغزو السلع والبضائع الأوربية للسوق العراقية اثر

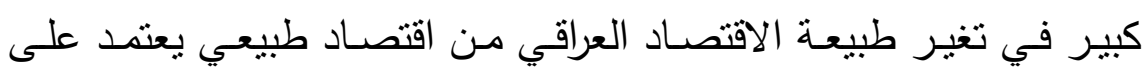
الإنتاج لسد الحاجة المحلية إلى اقتصاد السوق الذي يعتمد الربح. 
وقد أسهمت في أحداث كل تلك التغيرات عوامل داخلية وأخرى خارجية.

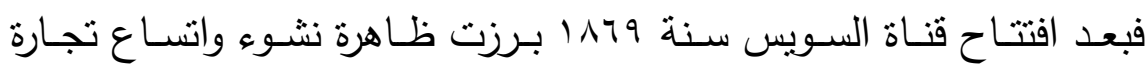

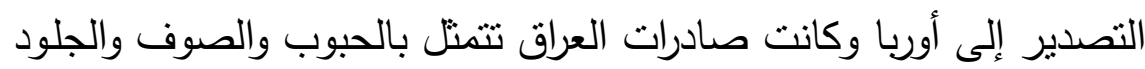

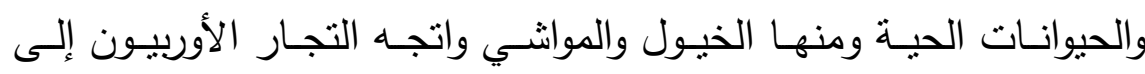

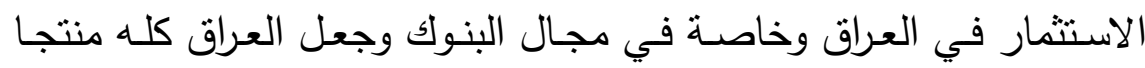

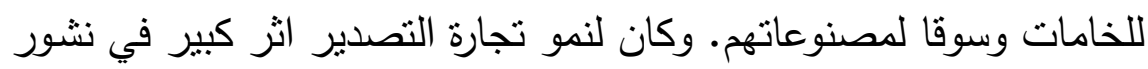
طبقة وسطى عراقية اقرب ما تكون الى الطبقة البرجوازية وكانت شريحة

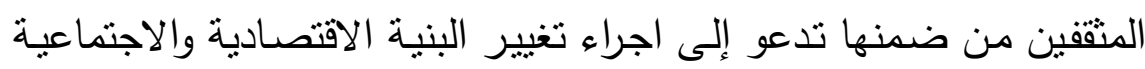

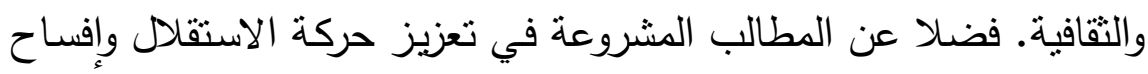
المجال للفئات والثرائح المحرومة لكي تتال حقوقها، وتعبر عن تطلعاتها.

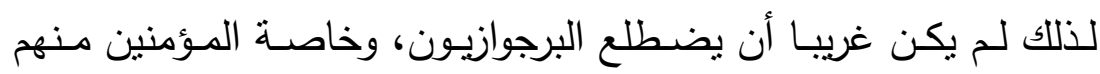

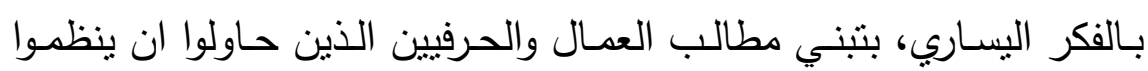

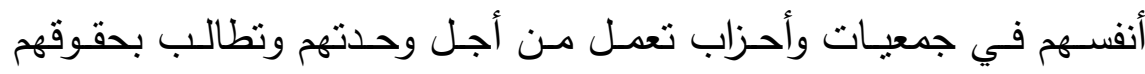

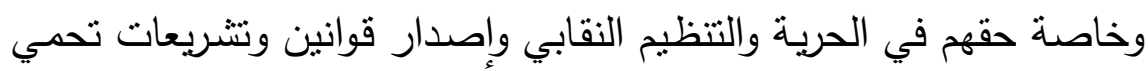

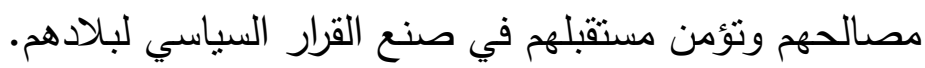

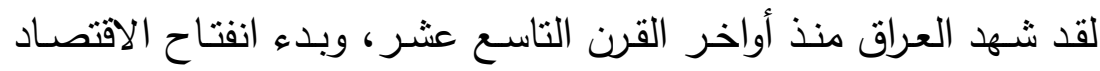

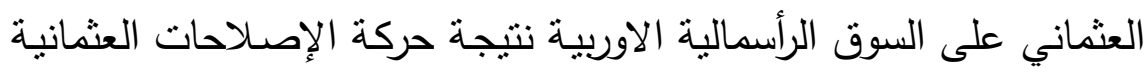

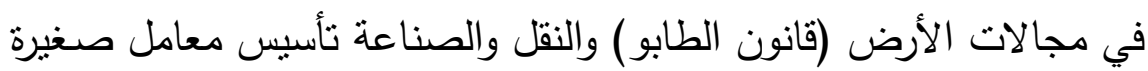

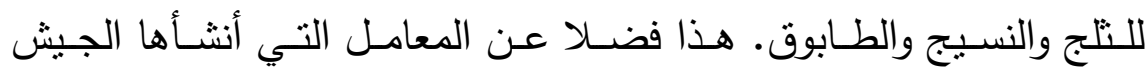

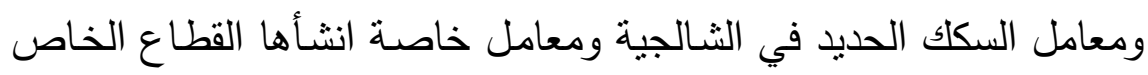
هنا وهناك من المدن العراقية وخاصة الكبرى منها بخداد والموصل والبصرة.

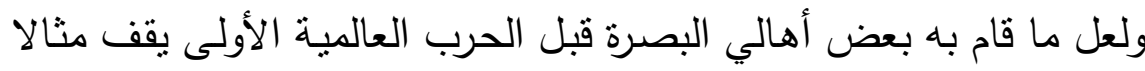

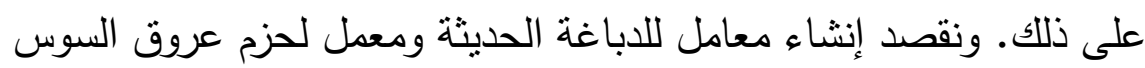
بقصد التصدير . كما تأسست شركة لتجارة المراكب وأخرى للنقل في البصرة 
وفي 19 19 دخلت السيارات العراق فتطورت اطرق المواصـلات ونمت

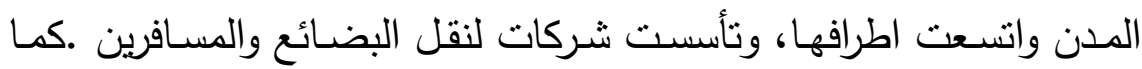

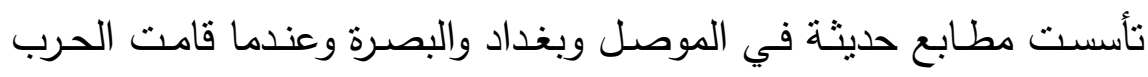

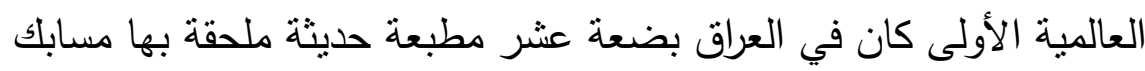

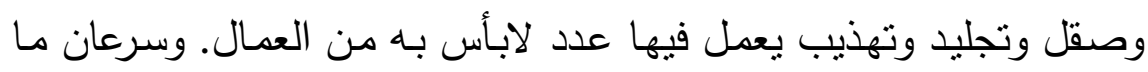

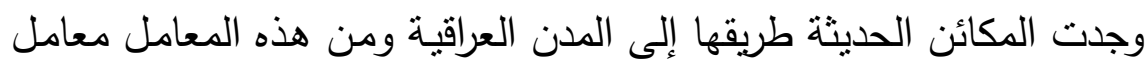
للتزج ومطاحن حديثة ومعامل لصنع المياه الغازية ومعامل للنسيج ومعامل

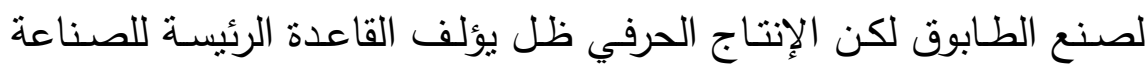

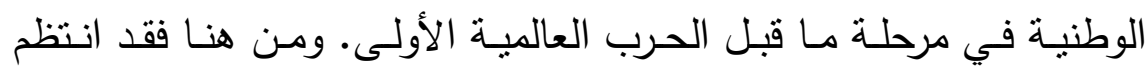

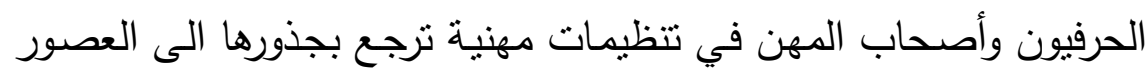

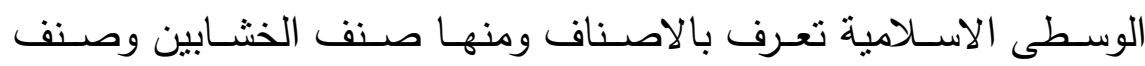
الصاغة وصنف العلافين وصنف السراجين.

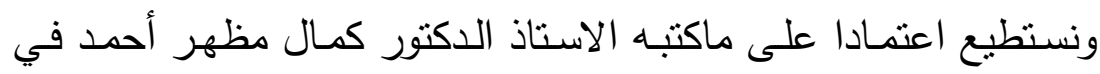

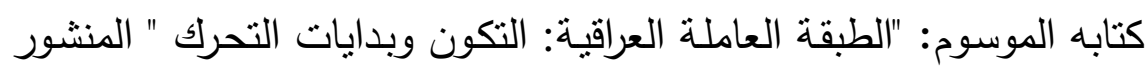

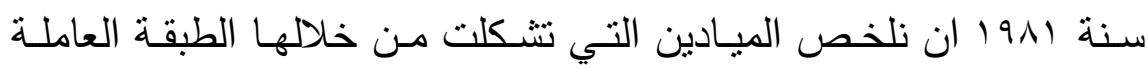
العراقية بثلاث هي: المعامل الحكومية والعسكرية ومنها معامل الحدادة في

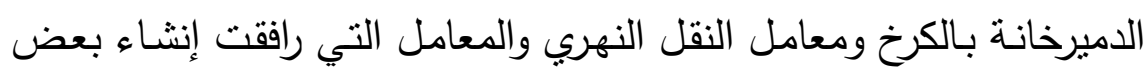

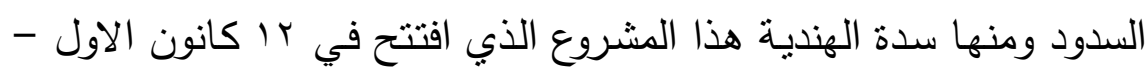
ديسمبر rا 19 واثتنغل فيه عمالا كثيرين تراوح عددهم بين الألف والثنلاثة

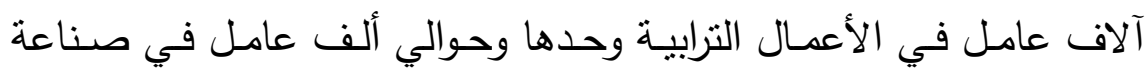

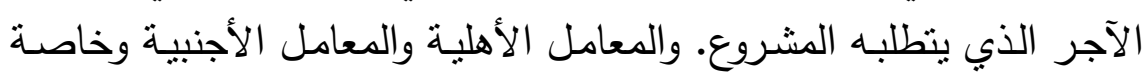

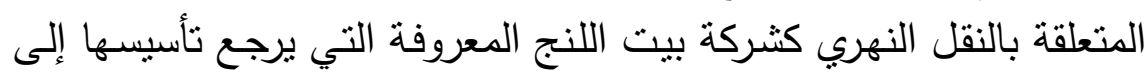

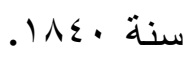

وخلال الحرب العالمية الأولى عانى العمال من شظف العيش ولم يكن

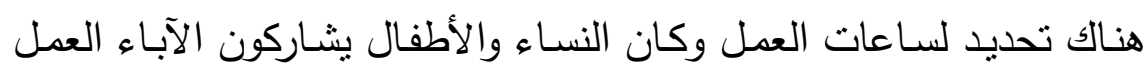


في ظـروف صـعبة للغايـة .وقد قـدر عدد العهـال العـراقيين الـائميين

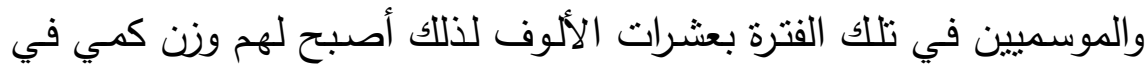

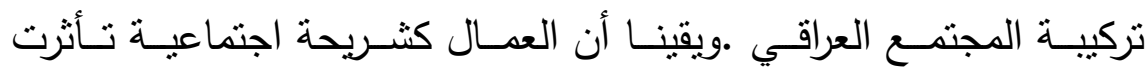

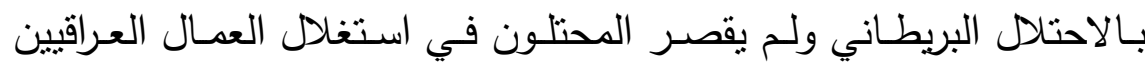

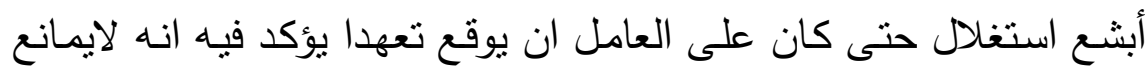

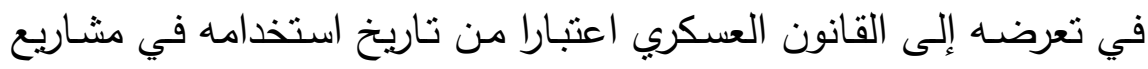

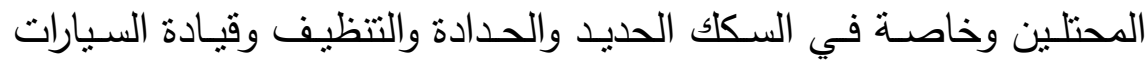

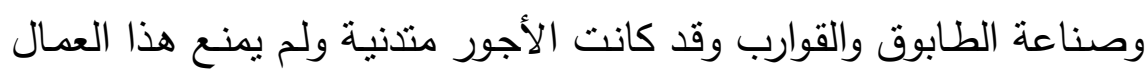

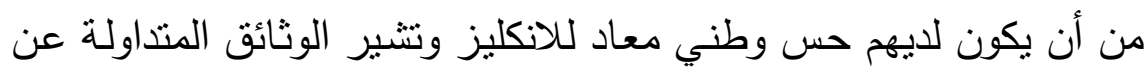

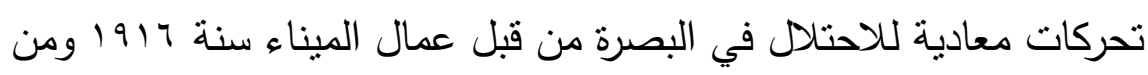

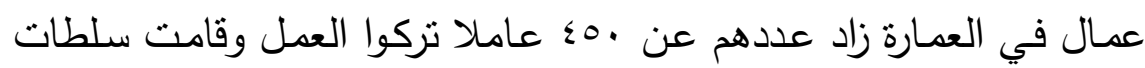

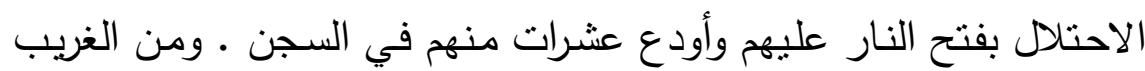

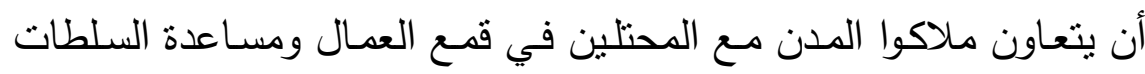

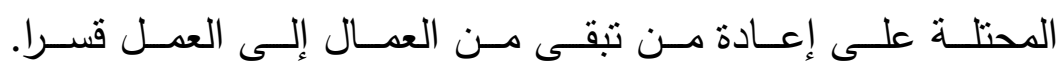

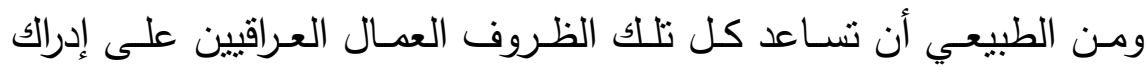

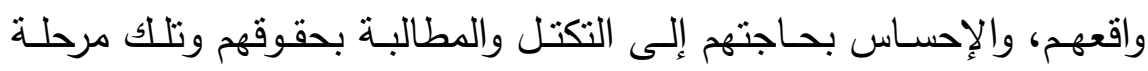
مهمة من مراحل تاريخ الحركة العمالية العراقية.

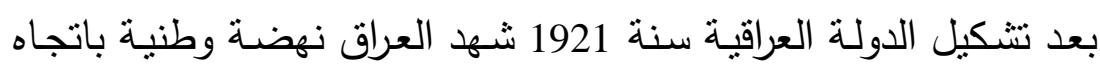

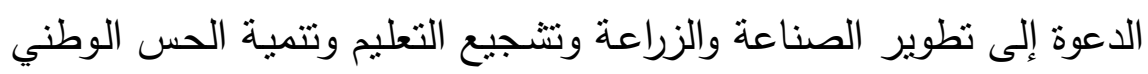

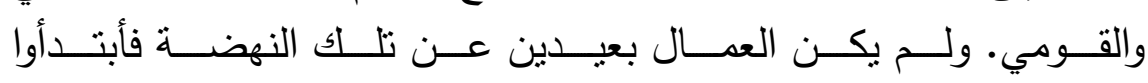

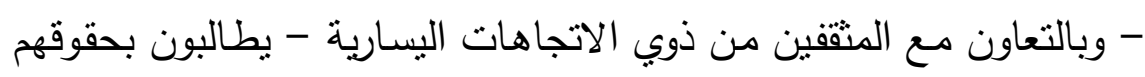

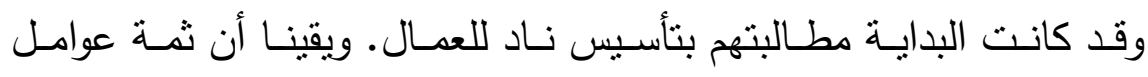

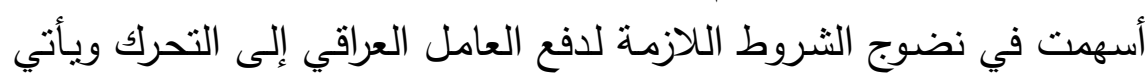

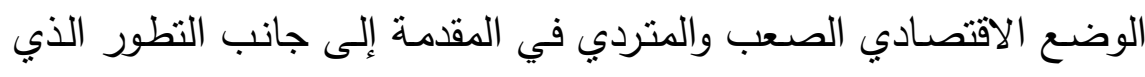

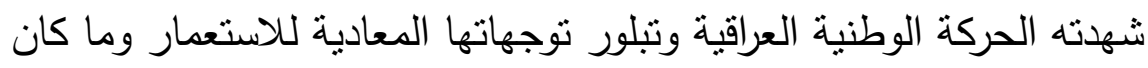


يسـعه العمـال مـن أخبـار عن تحركات العمـال في بعض البلدان ومنهـا

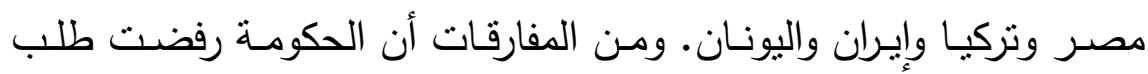

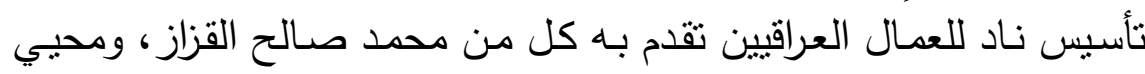
الدين محمد، وقاسم عباس، وهم عمال يعملون في السكك والمعمل العسكري

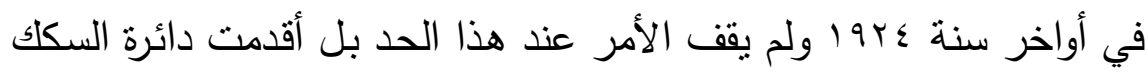

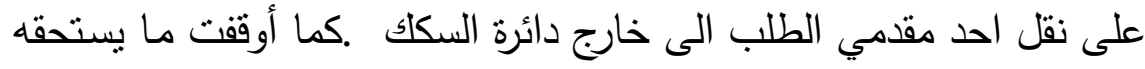

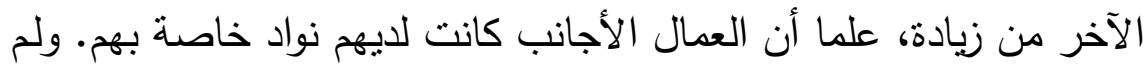
يفت هذا في عضد مقدمي الطلب وإنما تقدموا في مطلع سنة و9 9 أبطلب

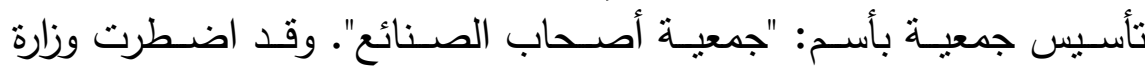

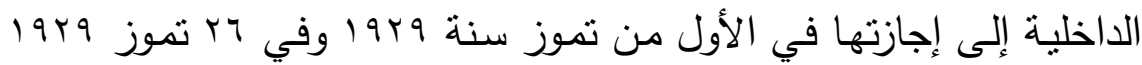

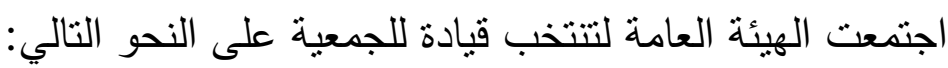
ا ـ ـ محد صالح عبد الجبار القزاز رئيسا. r. احمد السبد محمد عامل بالسكك نائبا للرئيس. r. محمد مصطفى ملاحظ في المعمل العسكري سكرنيرا.

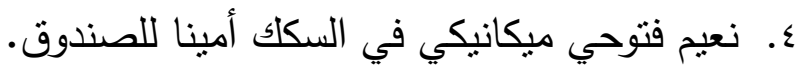
ه. يوسف السيد طه عامل ميكانيك بالسكك مراقبا عاما.

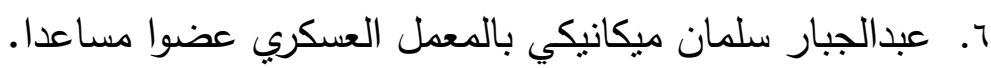

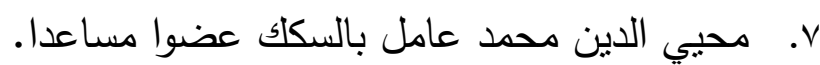

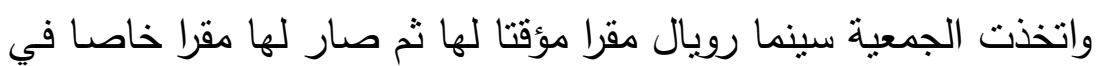

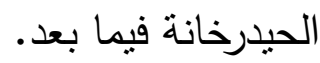

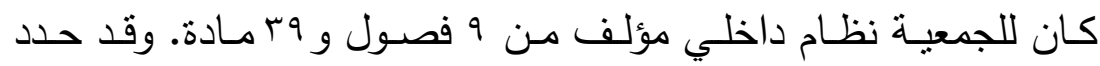

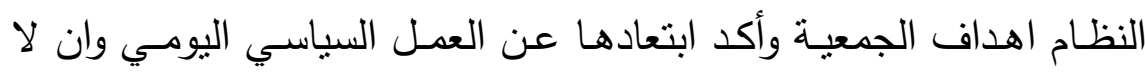

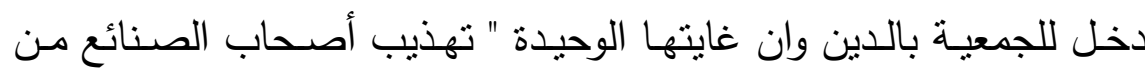
الوجهة الأخلاقية والصناعية والاجتماعية ونشر مبادئ الآداب الفاضلة بين

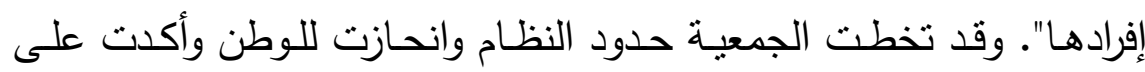


لسان مؤسسيها وخاصة القزاز إن غايتها الحقيقية " الدفاع عن حقوق العمال

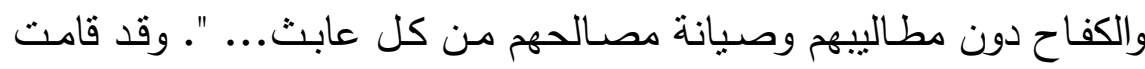

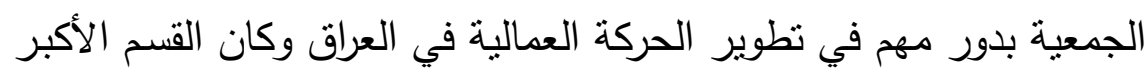

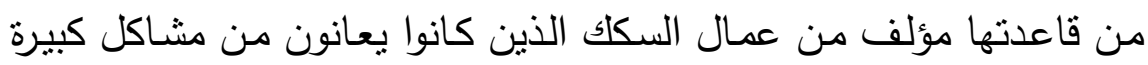

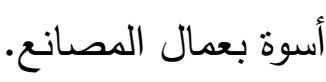

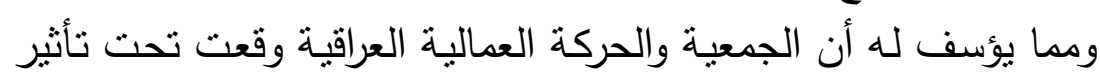

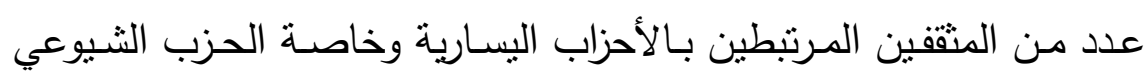

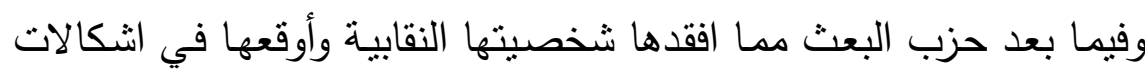

$$
\text { كثيرة لم تكن هي مسؤولة عنها. }
$$

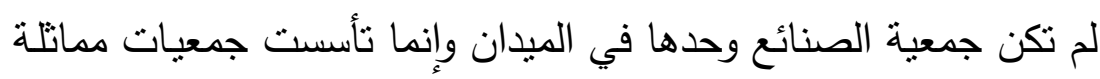

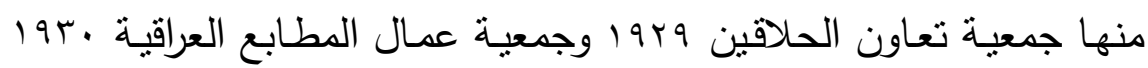

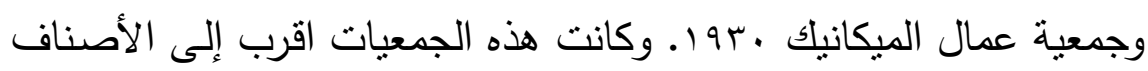
المهنية منها إلى الجمعيات العمالية الصرف.

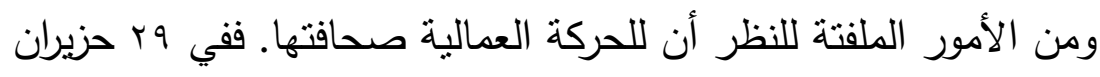

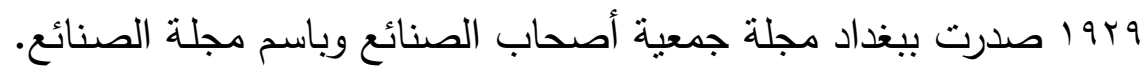

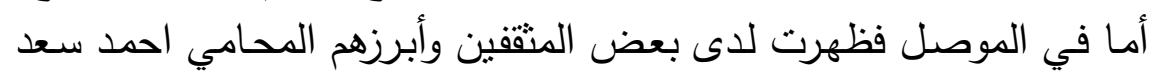

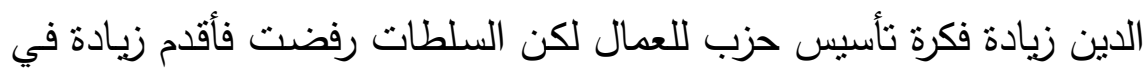

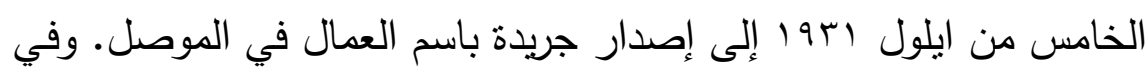

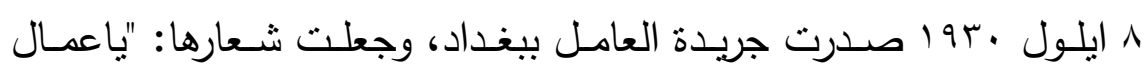

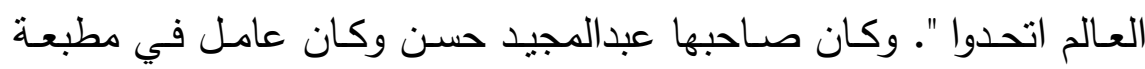

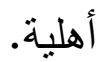

لقد استقطبت الحركة العمالية انتباه الماركسيين الأوائل كما يقول الأستاذ

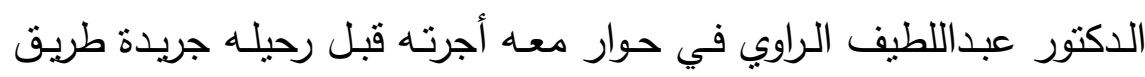

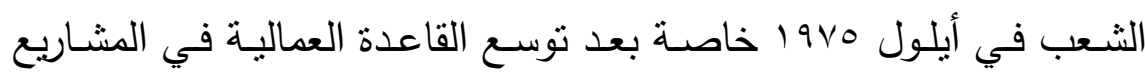

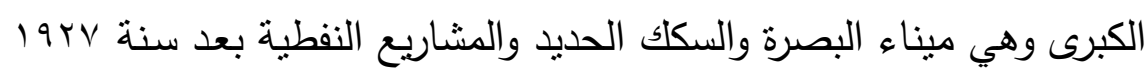


وكانت قضـاياهم المعيشية وعمليات الاستغلال الواقعة عليهم من الثركات

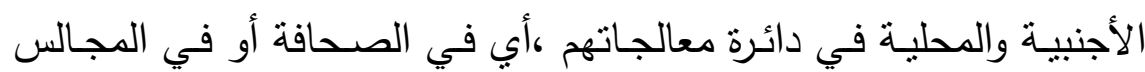

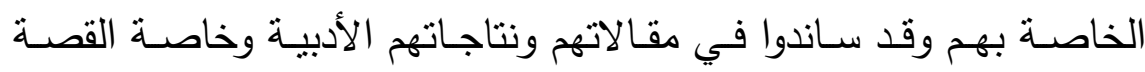

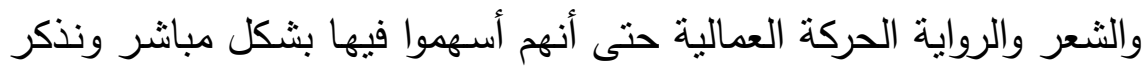
من هؤلاء المثقفين القاص محمود احمد السيد والقاص ذو النونه النون ايوب.

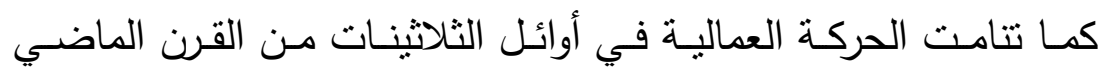

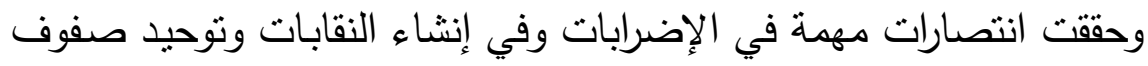

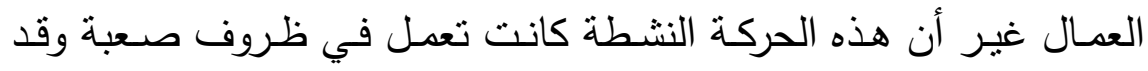

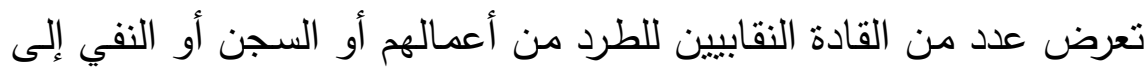
أماكن نائية من العراق.

شهر العراق إضرابات عمالية منذ زمن مبكر من تاريخ الحركة العمالية

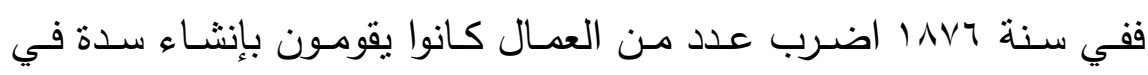

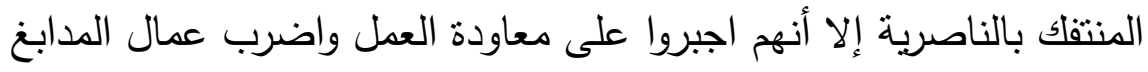

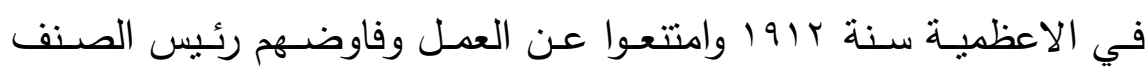

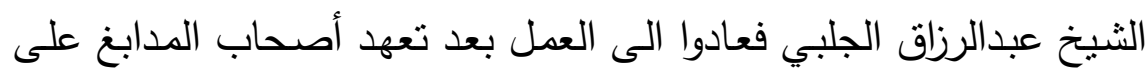

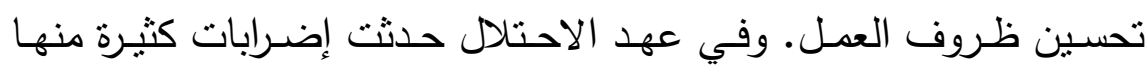
إضـراب في العمـارة سـنة VI9 ا وقد قامـت سـلطات الاحتنال بفتح النـار

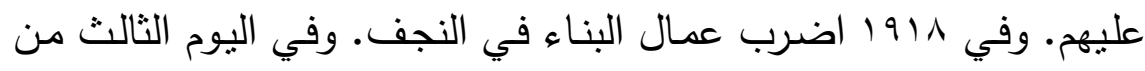

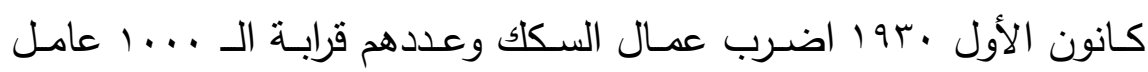
ورفعوا عريضة بمطالبهم وأبرزها تحديد اجورهم بما يستحقون ومنحهم أجورا

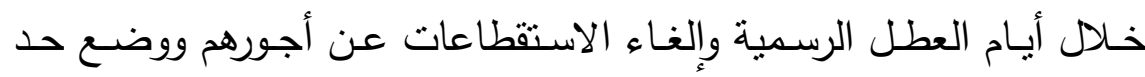

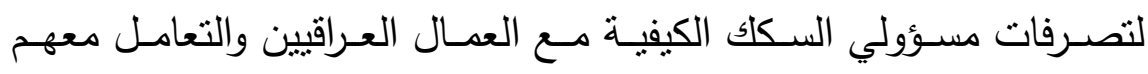

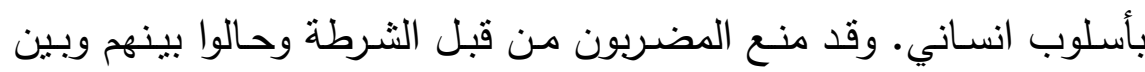

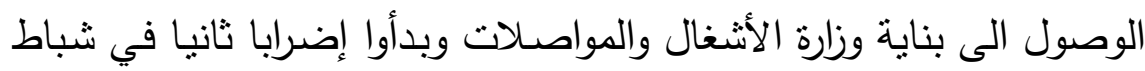
اب9 أوتبنت جمعيـة الصـنائع مطسالبهم وكـان اكبر مـن الإضـراب الاول. 


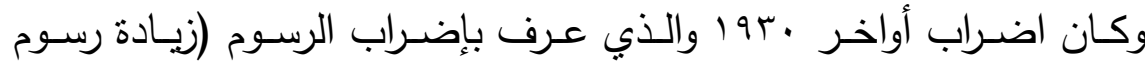

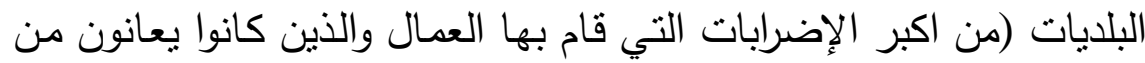

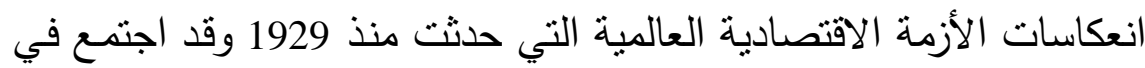

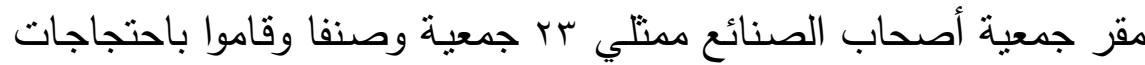

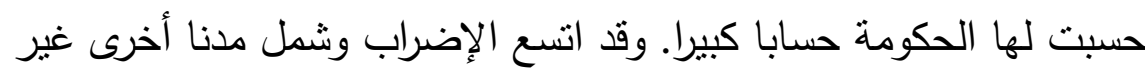

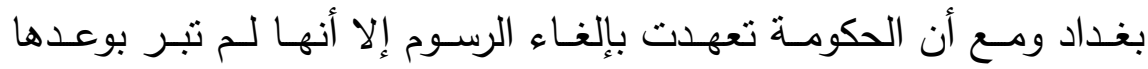

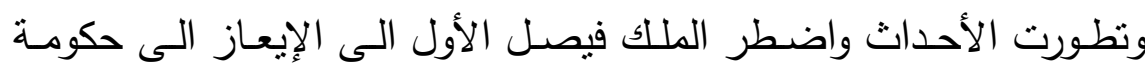

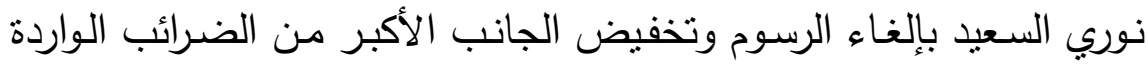

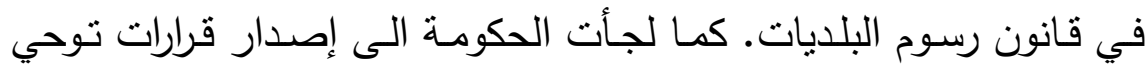

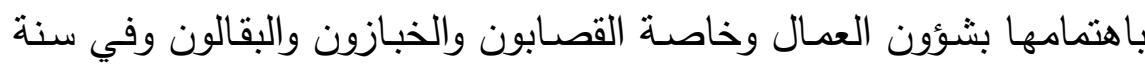

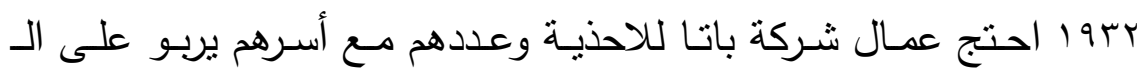
( وقعت الحرب العالمية الثانية 9 19 ـ 9 ـ فأسهوت ظروفها وانعكاساتها

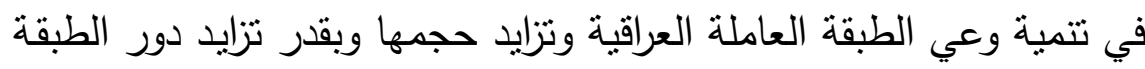

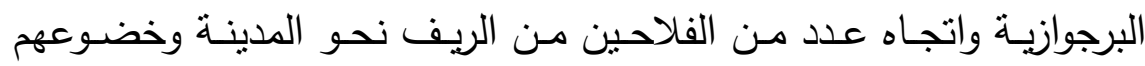

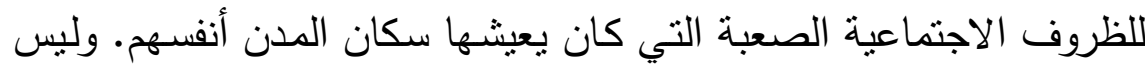

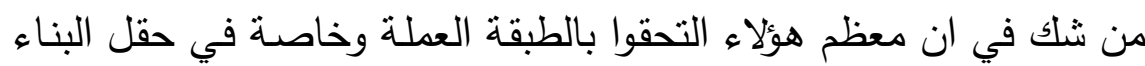

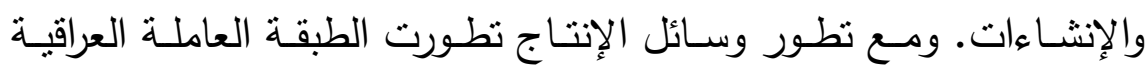

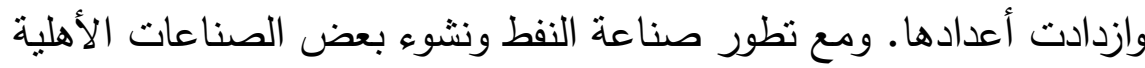

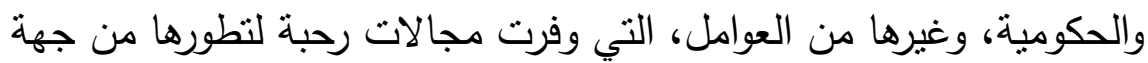

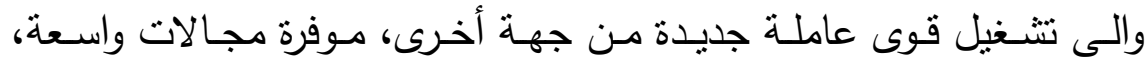
وحاجات كبيرة للأيدي العاملة الدائمية، ومحدثة تغينة تيبيرات ملحوظة في في تركيب

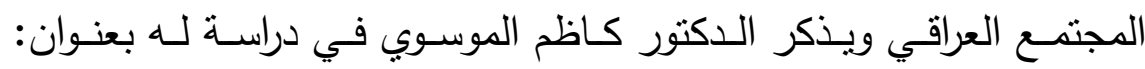

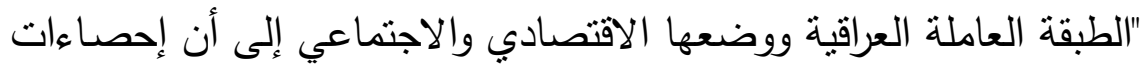

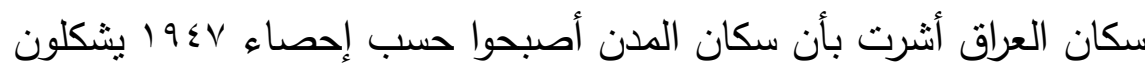


مـا نسبته \% اء من مجموع سكان العراق البالغ عددهم حوالي ^،؛ مليون

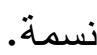
ومن المؤكد - كما سبق ان قدمنا -ان الزيادة هذه كانت على حساب أنساب

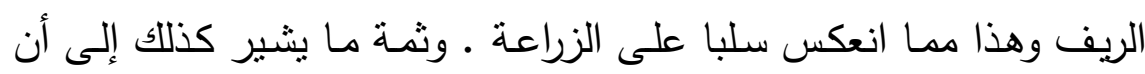

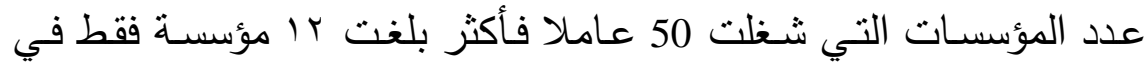

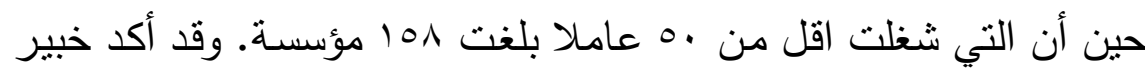

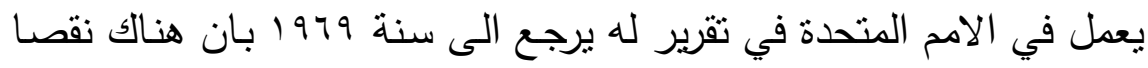

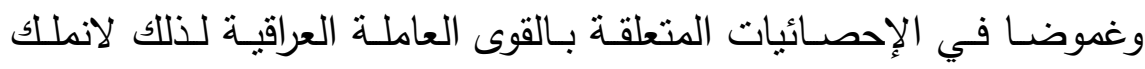

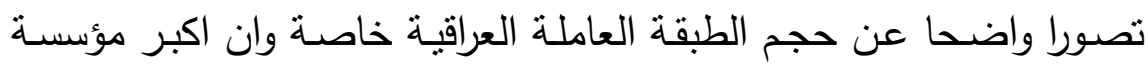

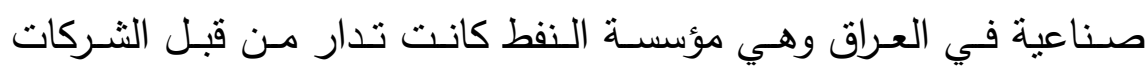

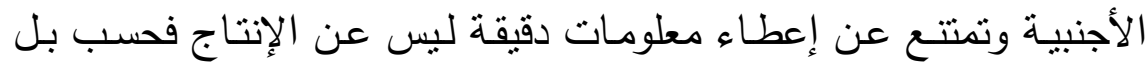
وحتى عن عدد العمال الذي يشتغلون لديها. ولم يختلف الحال بعد تطبيق

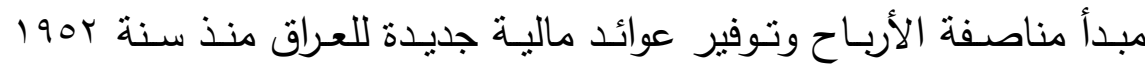

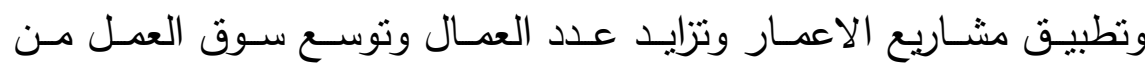
الناحيتين الكمية والنوعية. لقد أدى تطور إنتاج النفط وتوفر مجالات الكئن جديدة وفرص جديدة للعمل

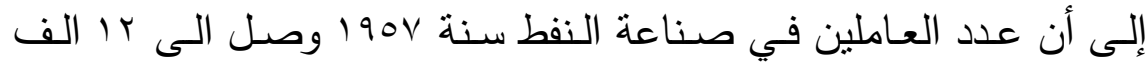

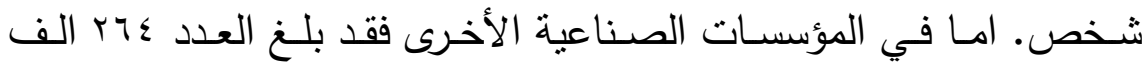

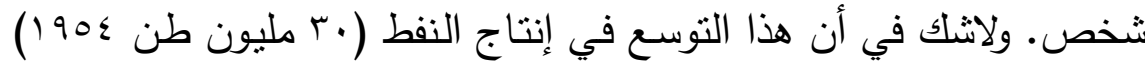

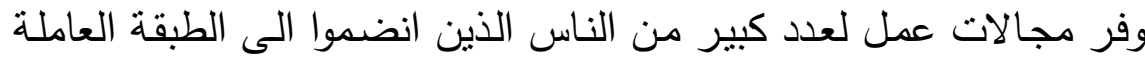

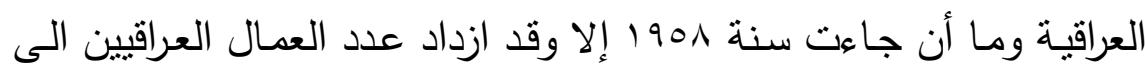

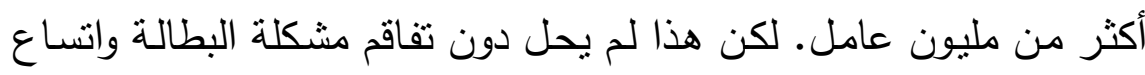

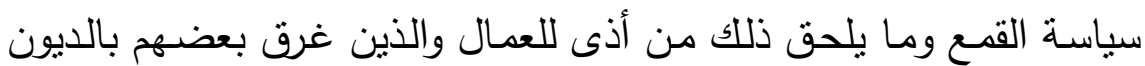

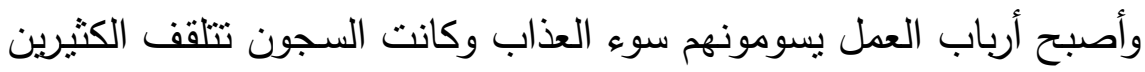
منهم وأصبحت النقابات والجمعيات العمالية عاجزة عن تقديم اي مساعدة العداب 


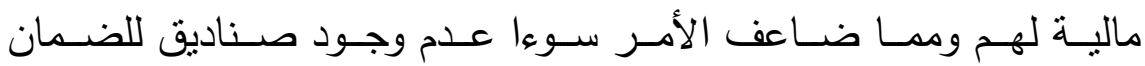

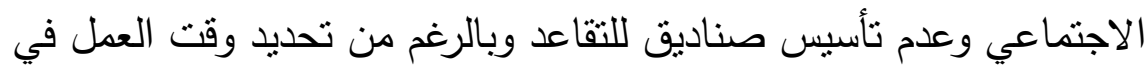

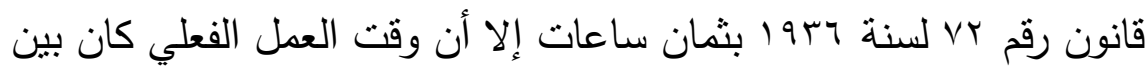

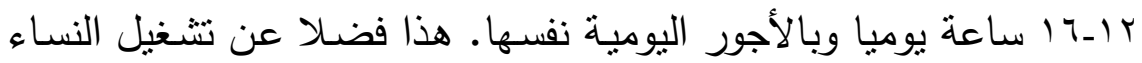
والأطفال والأحداث دون السن القانونية في أعمال شاقة وبأعداد كبيرة .وقد الأد العاء

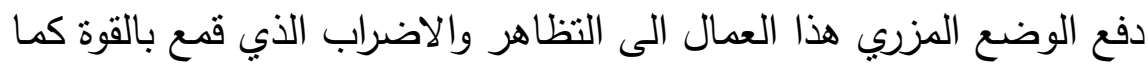

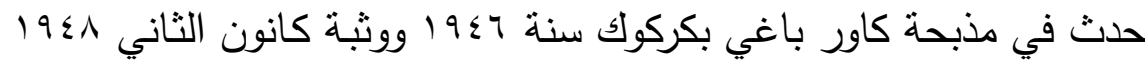

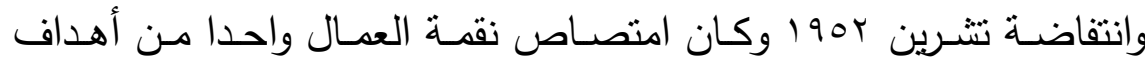

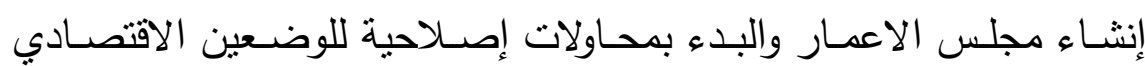

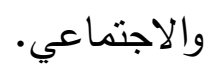

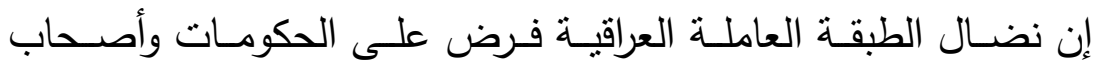

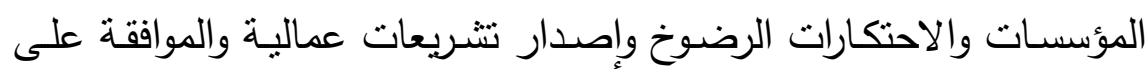
تأسيس نقابات وجمعيات عمالية.

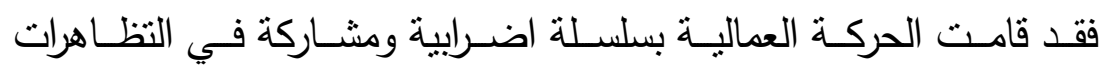

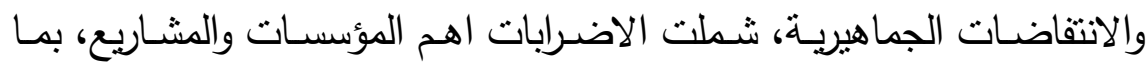
فيها القواعد العسكرية البريطانية، وسكك الحديد والنفط والكهرباء والميناء.

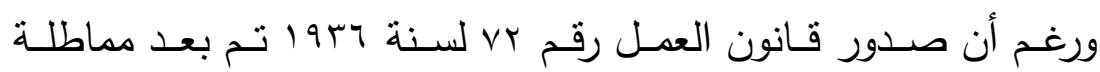

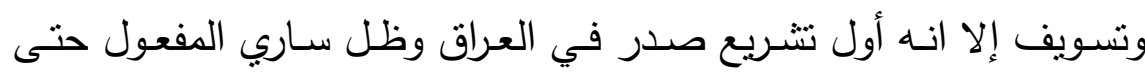

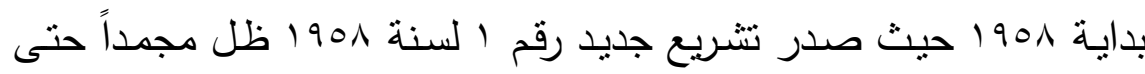

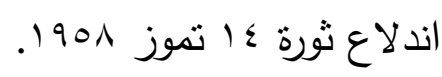

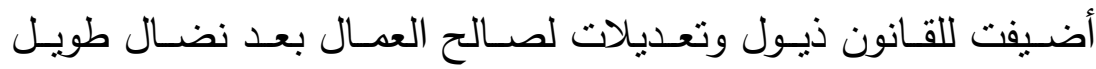

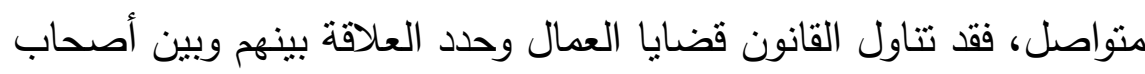

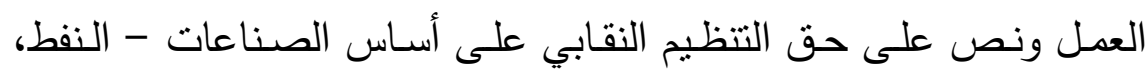

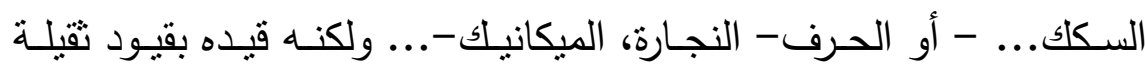
كإجازة وزير الداخلية وحسن السلوك من الثرطة، وجعله عرضـة للتعطيل 


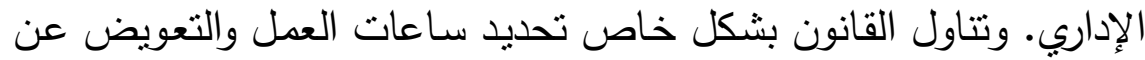

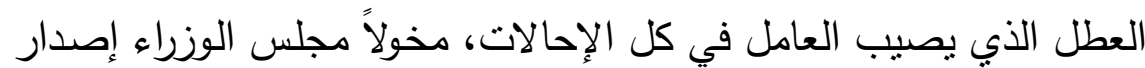

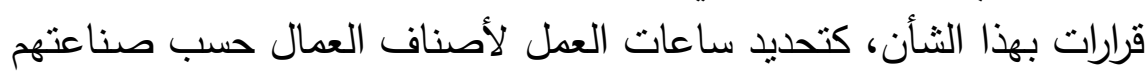
وحرفهم وجنسهم وأعمارهم وغيرها. إن اعتراف القانون بالتتظيم النقابي إقرار لواقع مارسـه العمال قبل هذا

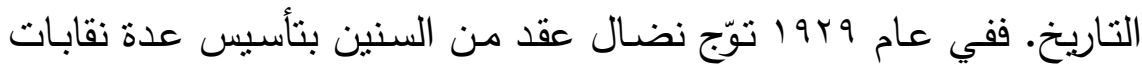

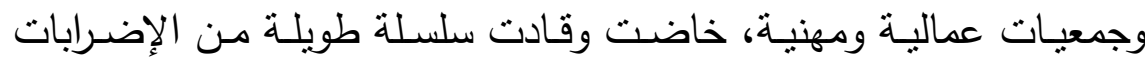

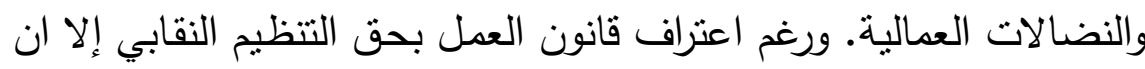

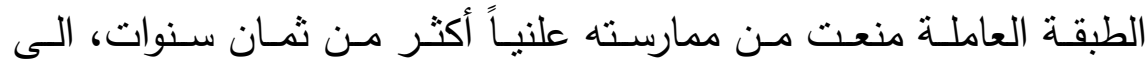

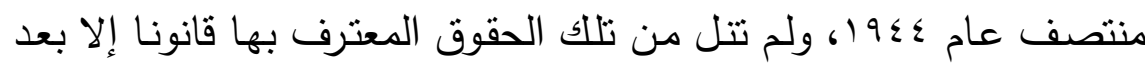

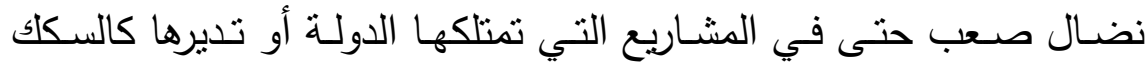

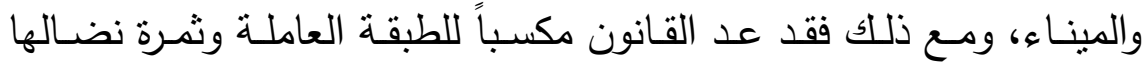
الباسل وتضحياتها منذ نشوئها، وتطوراتها، كانت نضانسالات الطبقة العاملة

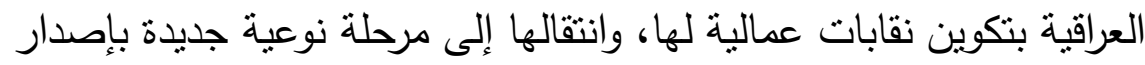

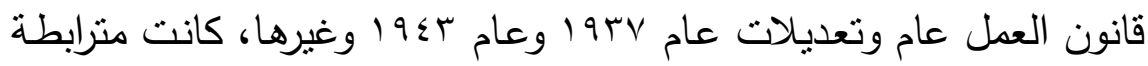

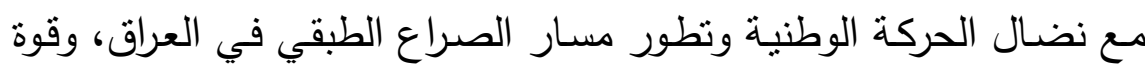
ومكانة الطبقة العاملة في المجتمع.

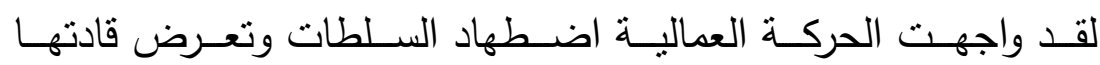

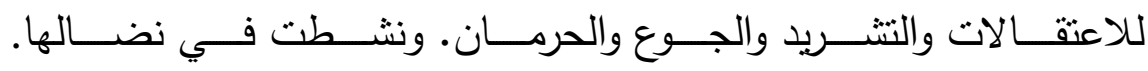

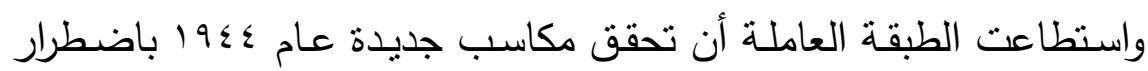

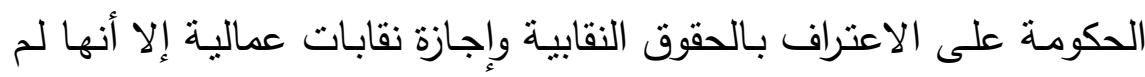

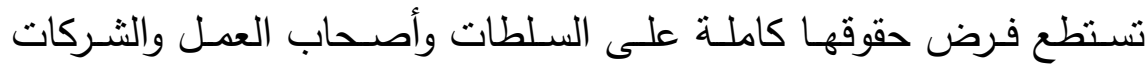

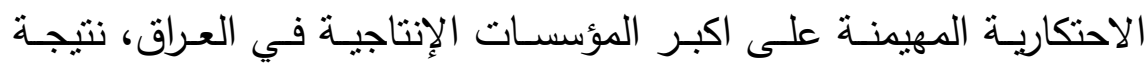

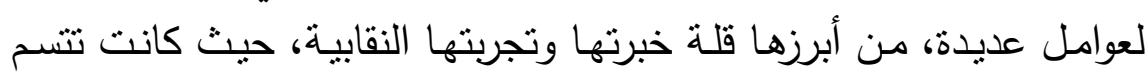

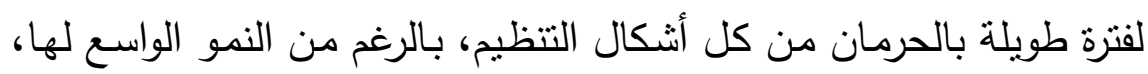


ومـا صـاحبها من متاعب جديـة وأوضـاع صسعبة وقعت تحت وطأتها فترة

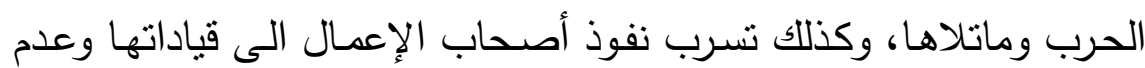

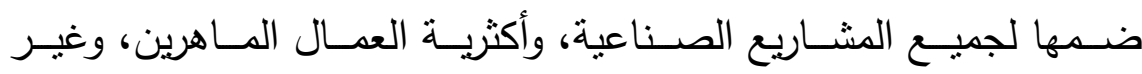

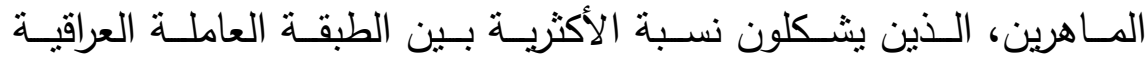
ومن بين المكاسب العمالية التي تمكنت الطبقة العاملة العراقية تحقيقها، بعد بله ov تضحيات ونضـالات متواصلة، إصدار " قانون الضمان الاجتماعي رقه لسنة 1907 ـ والذي كان أول قانون للضمان الاجتماعي للعمال في العراق.

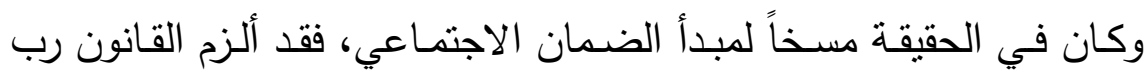

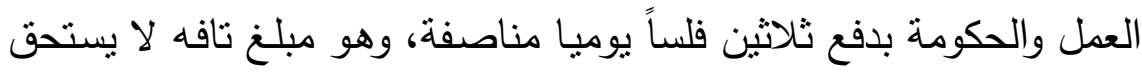

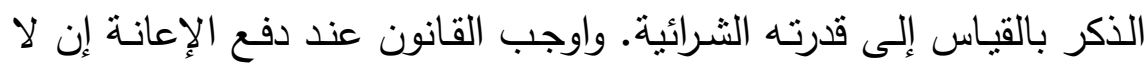
يكون العامل مشتركا في إضراب وان يكون قد نرك العمل باختياره وان يكون وانه حسن السلوك والسمعة. إن مما يمكنتا قوله أن الحركة العماليـة ارتبطت بالحركة الوطنبـة لذلك

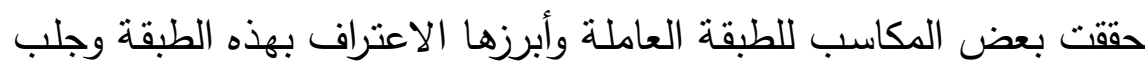

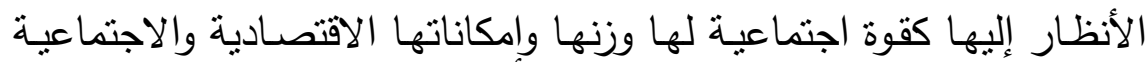
والسياسية .ولم يكن بوسع السلطة الحكومية تجاهل مطالب العمال ومن ذلك

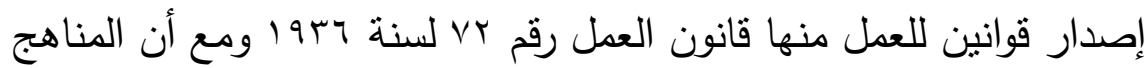

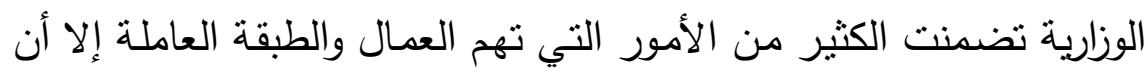

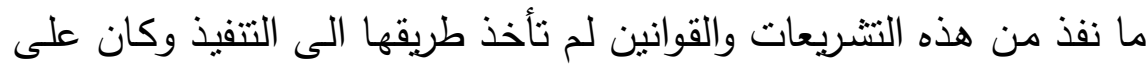

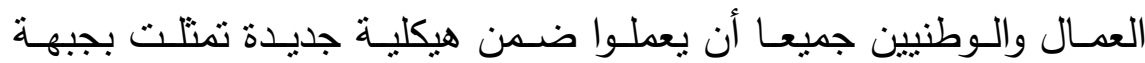
الاتحاد الوطني التي ضمت أحزابـا عراقية عديدة وتتظيم الضباط الأحرار

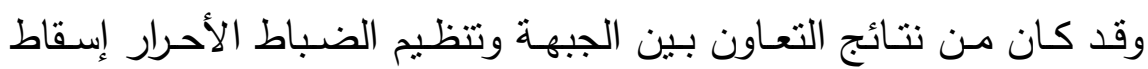

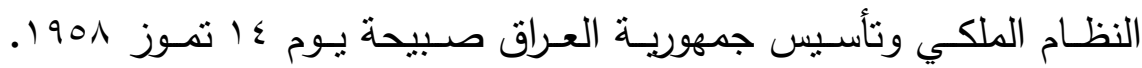
وبدأت عندئذ مرحلة جديدة من تاريخ الحركة العمالية في العراق. 
بعد ثورة ـا تمـوز 1901 سبطر الحزب الثيوعي على نقابـات العمال واستطاع تسيسها، وزجها في أتون الصراع السياسي مـع التيارات القومية. وقد انعكس ذللك سلبا على واقع ومستقبل الحركة العمالية وبعد سقوط نظام

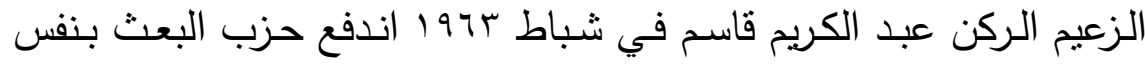

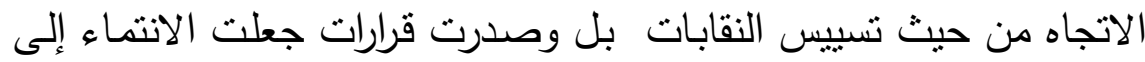
النقابات ليس إلزاميا. كما حولت شـريحة كبيرة من العاملين في مؤسسـات

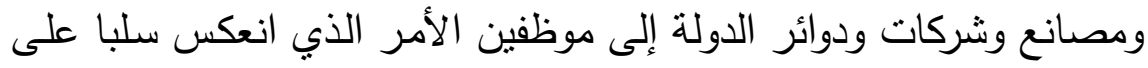

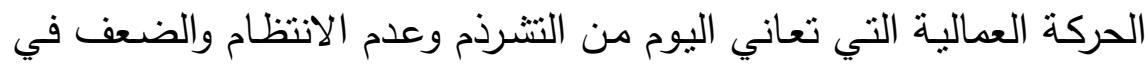

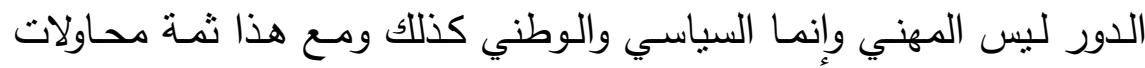

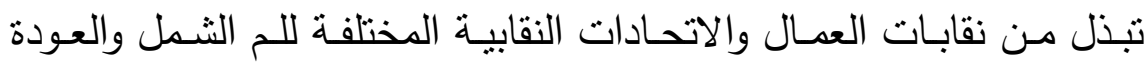
لممارسـة دورهـا الفاعل في بنـاء العراق من جديد ومعالجـة مـا اعتور كيانهـ السياسي والاقتصـادي والاجتمـاعي اثر الاحتلال الأميركي وإسقاط النظام

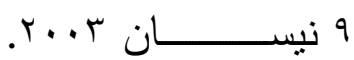
ابق ف

واليوم وبعد قرابة الـ ^ سنوات على سقوط النظام السابق يواجه الاتحاد

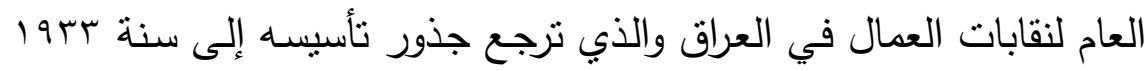

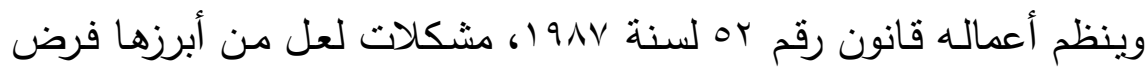

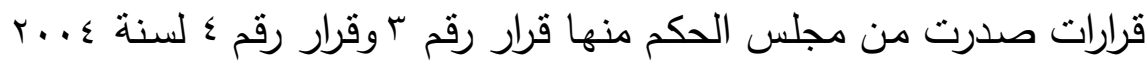

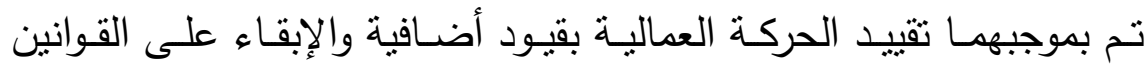

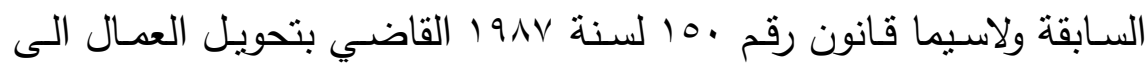
مـوظفين، وانعكاس حـالات المحاصصـة في التعامـل مـع الحركـة العماليـة والنقابيـة. وللأسف لم تتغير معانـاة العمال ولم تحل مشـاكلهم الاقتصـادية والاجتماعية.

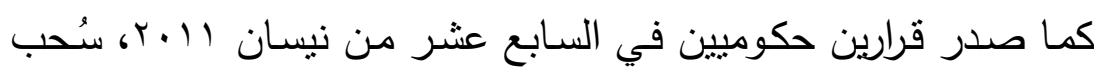

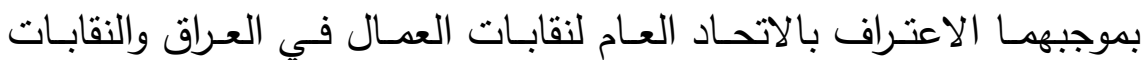


التابعة له، وبدلاً من ذلك جرى تشكيل "لجنة تحضيرية وزارية تقضي بوضع

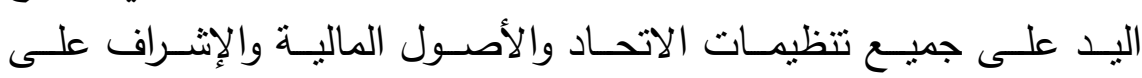
الانتخابات النقابية المقبلة. في حين أصدر (المكتب التنفيذي للاتحاد القائم

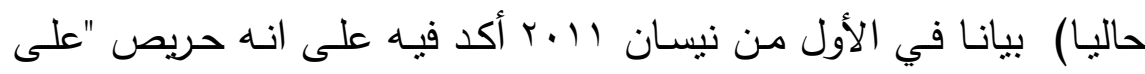
ترصين وتوحيد العمل النقابي في عموم المحافظات من خـلا توحيد خمسة

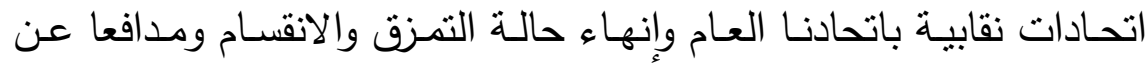

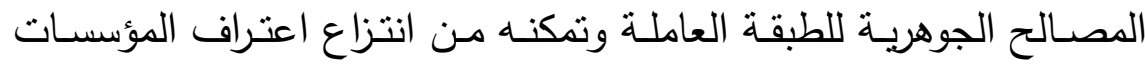

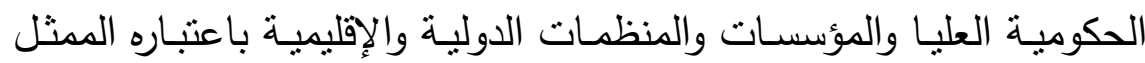
الثرعي والقانوني للحركة النقابية وباعتباره الوريث الشرعي للحركة النقابية

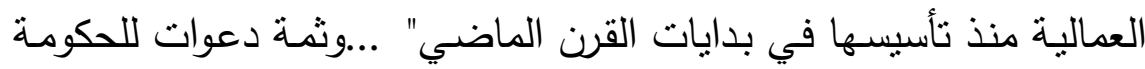

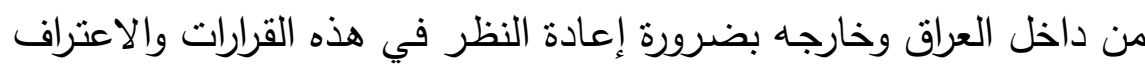
رسميا بما يسمى اليوم (الاتحساد العـام لنقابـات العمال في العراق) وهياكلهـ

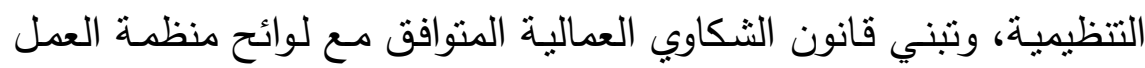
الدولية، والى ضمان حق جميع العمال في تشكيل النقابات والانتماء إليها، وتتظيم انتخاباتها بعيداً عن التخخل الخارجي والتسييس النقابي الذي اكتوت بناره الحركة العمالية العراقية لسنوات طوبلة مضت أنئ.

\section{History of Labor Movement In Iraq}

\section{Prof. Dr. Irahim Khalie AlALall \\ Head of Regianal Studies Center, University of Mosul}

Labor movement in Iraq is related to the developments happened since late of $19^{\text {th }}$ century, with regards to Ottoman reforms and modernization movement both in Ottoman Empire and the Iraqi provinces related to it and how such reforms had its effects on 
economic, social and political fields in changing the relationship between shykhs of tribes and peasants. What has weakened this relationship is the integration of Iraq's economy with the capital market and transformed it into market economy. The emergence of oil, expanding rail - roads and military equipments in addition to the rise of Iraqi Labor class in which it had become able in 1929 to organize for itself an Iraqi society for private works. Workers organizations had developed but unfortunately, they were the victom of struggles within the political powers and thus they were far from practicing their professionals and trade unions. This study is following up this topic and wish that Labors in Iraq may take the initiative in developing their organizations.,... 